\title{
Does Mortgage Hedging Amplify Movements in Long-term Interest Rates?*
}

\author{
Roberto Perli \\ Federal Reserve Board \\ Roberto.Perli@frb.gov
}

\author{
Brian Sack \\ Federal Reserve Board \\ Brian.Sack@frb.gov
}

August 2003

\begin{abstract}
The growth of the mortgage market in recent years has raised the question of what effects, if any, the hedging of mortgage portfolios has on the behavior of long-term interest rates. This paper finds that the volatility of the ten-year swap rate implied by swaptions increases when the prepayment risk of outstanding mortgages increasesmost likely because investors expect the hedging of prepayment risk to amplify future interest rate movements. These amplification effects can be considerable in magnitude, but they are generally expected to persist only for several months.
\end{abstract}

${ }^{*}$ The opinions expressed here are those of the authors and not those of the Board of Governors of the Federal Reserve System. We thank James Clouse, Michael Gibson, William Nelson, Michael Palumbo, Wayne Passmore, and Vincent Reinhart for helpful comments and discussions. 


\section{Introduction}

The growth of the mortgage market in recent years has been remarkable, with the amount of outstanding mortgage-related debt expanding by an average of more than 10 percent per year since 1998. Mortgage-backed securities, or MBS, grew even faster, at a 13.5 percent average rate, and are now the single largest segment of the fixed income market, representing almost a quarter of all marketable debt issued in the United States.

Mortgage-related debt differs from most other categories of debt in that it is subject to the risk of prepayment. Indeed, almost all mortgages written in the United States provide the mortgage payer with the right to prepay the mortgage without penalty - or, effectively, to call the loan at face value. Thus, mortgage securities embed a short position in a call option. The risk of prepayment has often been an important concern to the holder of mortgage-related debt, as recent years have been characterized by considerable amounts of refinancing activity reflecting a combination of a downward trend in market interest rates, a decline in the average cost of mortgage refinancing, and perhaps greater sophistication on the part of mortgage payers.

Because of the rapid growth of the market, investors who hold mortgage-related securities in their portfolios and desire to hedge the prepayment risk of those securities are now, in the aggregate, required to buy or sell much larger quantities of other financial instruments. This type of hedging has the potential to reinforce existing market trends. Such effects can arise under a variety of hedging strategies, but they are perhaps best understood in a simple example of dynamic hedging. A decline in market interest rates, say, causes an increase in prepayment risk that reduces the duration of outstanding mortgage-related securities. Holders of those securities who want to maintain the duration of their portfolios would then have to purchase other longer-term fixed-income securities to add duration, thus potentially causing yields to fall further. Similar effects tend to amplify increases in market interest rates as well.

It is indeed a common view among fixed-income market participants that mortgage hedging activity has frequently amplified movements in long-term interest rates. In this paper we seek empirical evidence on the magnitude and significance of these effects. More specifically, we show that these effects, if they exist, have two implications for the behavior of the volatility of long-term interest rates. First, periods of heightened prepayment risk

should be associated with a higher level of volatility, as hedging activity would be expected to 
reinforce movements in interest rates that might have otherwise occurred. Second, we show that volatility itself should be more volatile during periods of heightened prepayment risk. These predictions are borne out in the swaptions market, indicating that MBS hedging does in fact appear to have a significant impact on the expected behavior of long-term interest rates.

The rest of the paper is organized as follows. In section 2, we discuss various prepayment risk hedging strategies and argue that all should result in an amplification of market interest rates. In section 3, we lay out the analytical framework of our analysis. In section 4, we present the results of our estimation. In section 5, we summarize our findings and offer some alternative interpretations and concluding remarks.

\section{Mortgage Hedging and Interest Rate Volatility}

As noted in the introduction, the mortgage market has grown very rapidly in recent years, and a growing share of mortgages have been pooled into mortgage-backed securities. The growth of MBS has far outstripped the growth of other types of marketable U.S. debt, as is evident from Figure 1. At the end of 2002, the quantity of outstanding MBS was well in excess of $\$ 4$ trillion, and mortgage-backed debt is now the largest single class of marketable debt outstanding. ${ }^{1}$

Mortgage-backed securities are held by a variety of investors, although there are several large participants in the market. Fannie Mae and Freddie Mac, the two largest mortgage holders, had a combined $\$ 1.38$ trillion worth of mortgages and MBS in their portfolios at the end of 2002. Other large MBS holders are commercial banks, which are attracted by their superior yields and little or no credit risk.

The increased size of the mortgage market has brought with it an increased need among mortgage holders to manage interest rate risk, taking into consideration the effects of prepayment risk. Mortgages and mortgage-backed securities have what is referred to as "negative convexity," which means that the price of these securities is concave in the market interest rates, in contrast to the convex relationship between the price and yield of a typical bullet debt security. The negative convexity arises from the ability of mortgage payers to refi-

\footnotetext{
${ }^{1}$ The source of the data in the figure is the Flow of Funds Accounts of the United States. The duration and convexity data we use below for mortgage-related debt refer instead to the Merrill Lynch mortgage master index. At the end of 1995, the value of this index was only about 55 percent of the value of their Treasuries master index; by the end of 2002, its value had more than doubled, reaching a level that was about 25 percent bigger than the Treasuries master index. These percentages are roughly comparable to those obtained from the Flow of Funds data.
} 




Figure 1: Outstanding amounts of various fixed-income securities

nance their mortgages at par value. As mentioned above, this prepayment ability implies that the typical U.S. fixed rate mortgage embeds a short position in a call option (held by the mortgage payer). This option becomes more valuable as market interest rates fall, hence limiting or even reversing the capital gains on the mortgage security. The increased prepayment risk associated with the decline in interest rates also causes the duration of the mortgage to shorten, thereby changing the interest rate exposure of the investor's portfolio going forward. These effects operate in the opposite direction in response to an increase in interest rates: The duration of the mortgage will increase, and the decline in its price will be more pronounced than for other "positively convex" fixed-income securities.

It is likely that mortgage holders will attempt to offset some of the variation in duration that results from this prepayment risk. This is clearly the case for Fannie Mae and Freddie Mac, for whom we have some public information about their hedging activity. Indeed, both of these institutions have guidelines by which they seek to keep the net total duration of their balance sheets within a specified range around zero, thus requiring them to hedge or dynamically offset some of the changes in duration arising from shifts in prepayment risk. Market reports suggest that there are other large participants with a similar trading strategy, although not on the same scale as these government-sponsored enterprises.

In principle, investors could follow a number of strategies to hedge their mortgage port- 
folios. One of the most straightforward approaches is dynamic hedging. Under this strategy, investors would buy or sell certain fixed-income securities or derivatives as interest rates change in order to offset changes in the duration of their mortgage portfolios. For example, if investors were hedging their mortgage holdings by shorting other debt instruments such as Treasuries or agencies, then they would have to reduce those short positions as duration declines and increase them as duration increases. This dynamic hedging strategy therefore causes investors to purchase debt securities precisely when rates fall and, conversely, to sell when rates rise - behavior that might amplify movements in market interest rates. A similar effect arises if investors hedge with swaps rather than bullet debt securities. ${ }^{2}$ In that case, investors would seek to increase their receive-fix swap positions when rates decline and their pay-fix swap positions when rates increase. These adjustments would have a similar effect in terms of amplifying interest rate movements as purchasing other debt securities.

In the case in which mortgage holders attempt to maintain the duration of their portfolios (at zero in the above example), the extent to which they would have to adjust their hedging positions in response to a change in market interest rates is determined by the convexity of their MBS holdings, since convexity measures the amount by which duration changes with changes in market interest rates. Because of the size of the MBS market, the potential magnitude of this type of hedging activity is large. According to measures that we develop in more detail below, as of March 23, 2003, a decrease (increase) in market interest rates of 50 basis points would have generated a shortening (lengthening) of MBS duration such that, to perfectly offset this change in duration, investors would have had to receive (pay) fixed payments in $\$ 289$ billion of new ten-year swap agreements. ${ }^{3}$

There are a couple of factors that might damp the market implications of this type of hedging. First, the entire mortgage market does not completely hedge their duration risk. But even if a fraction were doing so, the portfolio flows would be considerable. Second, market participants may use a variety of strategies that are more complicated than those outlined above to achieve their hedging objectives. However, these market implications are still likely to be realized under these alternative strategies. To see this more clearly, we

\footnotetext{
${ }^{2}$ Although dynamic hedging could be done with Treasuries, it appears that swaps have become a preferred hedging instrument for many investors (see, for example,[3]). This was clearly the case when investors were concerned about the potential paydown of Treasury debt (in 2000) and the consequences for liquidity. However, more recent anecdotal evidence suggests that a considerable amount of hedging activity has switched back to Treasuries.

${ }^{3}$ Here we are ignoring the asymmetry that arises because of the non-linearity of the price of the embedded option. The asymmetry increases as the magnitude of the interest rate change increases.
} 
describe several of the alternative strategies here.

One possibility is that investors could adjust the duration of their liabilities, rather than the duration of their other assets. Of course, this simply passes the portfolio adjustment on to other investors. For example, in response to a lengthening in mortgage duration due to a rise in long-term rates, a firm could simply issue more long-term liabilities in order to leave the net duration of its balance sheet unchanged. Obviously, though, some investor must purchase these longer-term liabilities, and so the effect on market interest rates should be nearly the same as if the firm had sold some of its other long-term assets.

Another possibility is that mortgage holders could finance their portfolio with callable debt, or they could synthetically create callable debt by issuing non-callable debt and purchasing appropriate option instruments such as swaptions. Only large investors, such as Fannie Mae and Freddie Mac, appear to use outright callable debt, and they typically do so in a relatively small proportion since they can achieve the same result more efficiently in the derivatives market (see [4]). Thus, the more relevant type of hedging to consider involves the use of swaptions and other options such as caps and floors. Buying swaptions, for example, provides the mortgage holder with convexity, therefore offsetting or reducing the negative convexity of mortgages. ${ }^{4}$ Again, though, this strategy simply passes the negative convexity exposure to another investor, the one selling the swaption to the mortgage holder.

Overall, all of the static hedging strategies that are possible involve passing the risks associated with the negative convexity of mortgages on to other investors. Thus, these strategies likely will not mitigate the market effects of prepayment risk to any great extent. ${ }^{5}$ In the aggregate, changes in the prepayment risk of mortgages still result in significant shifts in the duration and convexity of the securities available in the fixed income market, as those shifts in duration and convexity flow to the household sector (or the mortgage payers in general). These aggregate adjustments, because of their considerable magnitudes, are quite likely to have implications for the behavior of long-term interest rates.

Other authors have addressed the problem of the effect of mortgage hedging on other

\footnotetext{
${ }^{4}$ In particular, receive-fix swaptions provide a hedge against declining rates, while pay-fix swaptions provide a hedge against increasing rates.

${ }^{5}$ A natural supplier of swaptions to mortgage hedgers might be the Federal Home Loan Banks (FHLBs). The FHLBs lend to their member institutions via convertible advances, which are fixed-rate advances that they have the option to convert to variable-rate prepayable advances. They can then sell these options to dealers, who might convert them into swaptions and sell them to mortgage investors. To the extent that the FHLB system provides large quantities of swaptions through this channel, the impact of this type of static hedge on other market interest rates might be mitigated.
} 
interest rates. Fernald et al.,[2], describe the puzzling behavior of the yield curve following the 125 basis points tightening of target federal funds rate between February and May 1994. At that time the yield curve failed to flatten, as it typically does when policy tightens; long rates actually started to rise in October 1993, and by May 1994 they were 133 basis points higher. Fernald et al. ascribe this atypical behavior to the selling of Treasury securities by holders of large fixed-rate mortgage portfolios and MBS dealers, who experienced an unexpected surge in mortgage duration and needed to sharply adjust their hedging positions as rates increased. Kambhu and Mosser, [5], consider the effect on the yield curve of options hedging in general, rather than mortgage hedging. Since a sizable part of mortgage hedging is done with option instruments, their results can be relevant for our purposes. They conclude that options hedging can push rates further in the direction they are already moving, and that these "feedback" effects can alter the shape of the yield curve and make it harder to extract information about future economic developments. Crawford et al., [1], also show that convexity hedging of mortgage portfolios can help explain movements in implied volatility, although they do not provide actual estimates.

\section{An Empirical Framework}

In this section we develop an empirical framework that will allow us to quantify the effects of MBS hedging and to determine whether those effects are statistically significant. The specification captures the idea that movements in long-term interest rates may be amplified during periods when prepayment risk is elevated.

More specifically, we assume that movements in long-term interest rates are determined by the following equation:

$$
\Delta r(t, t+n)=\sqrt{\gamma_{t}} \cdot \varepsilon(t, t+n)
$$

This equation assumes that changes in the ten-year swap rate between time $t$ and $t+n$, denoted $\Delta r(t, t+n)$, are driven by a "fundamental" shock over that period, $\varepsilon(t, t+n)$, that captures the influence of the normal determinants of interest rates-including macroeconomic news, monetary policy developments, and shifts in investors risk preferences. ${ }^{6}$ The effects of this shock are scaled by an "amplification" factor, $\sqrt{\gamma_{t}}$, which captures the influence of mortgage-related hedging activity. The amplification factor is known at time $t$,

\footnotetext{
${ }^{6}$ We will be more specific about the horizon over which the interest rate changes are measured in the next section.
} 
which captures the notion that it is the condition of the mortgage market at the beginning of the period that can result in amplification of any subsequent interest rate movements.

The amplification factor is specified to allow fundamental shocks to have a larger impact during periods of significant mortgage prepayment risk. When mortgage hedging activity is light, the parameter $\gamma$ will be close to 1 , so that fundamental shocks pass through to long-term interest rates about one-for-one. However, during periods of intense mortgage hedging, $\gamma$ will be allowed to rise above 1 . We will discuss the specification of this factor in detail below.

Based on equation (1), the variance of interest rate changes is given by:

$$
\sigma_{\Delta r, t}^{2}=\gamma_{t} \sigma_{\varepsilon, t}^{2}
$$

where $\sigma_{\Delta r, t}^{2}$ represents the variance of $\Delta r(t, t+n)$ conditional on information at time $t$, and $\sigma_{\varepsilon, t}^{2}$ represents the "fundamental" variance of the rate that would have been expected in the absence of mortgage hedging activities. It has been well documented in the GARCH literature that the variance of interest rates demonstrates considerable persistence, which likely arises in large part from persistence in the volatility of the fundamental shocks that affect those rates. To allow for this possibility, we assume that the conditional variance of the fundamental shock follows a first order autoregressive process:

$$
\sigma_{\varepsilon, t}^{2}=\alpha_{0}+\alpha_{1} \sigma_{\varepsilon, t-1}^{2}+u_{t}
$$

Equations (1) to (3) represent all of the structure that we need to derive our empirical equation. Substituting equation (3) into equation (2) gives us the following expression for the volatility of the interest rate:

$$
\sigma_{\Delta r, t}^{2}=\alpha_{0} \gamma_{t}+\alpha_{1} \gamma_{t} \sigma_{\varepsilon, t-1}+\gamma_{t} u_{t}
$$

Using equation (2) to express $\sigma_{\varepsilon, t-1}^{2}$ as $\sigma_{t-1}^{2} / \gamma_{t-1}$, we can rewrite equation (4) as:

$$
\sigma_{\Delta r, t}^{2}=\alpha_{0} \gamma_{t}+\alpha_{1} \frac{\gamma_{t}}{\gamma_{t-1}} \sigma_{\Delta r, t-1}^{2}+\gamma_{t} u_{t}
$$

Equation (5) provides the specification that is the basis for our empirical work.

Under this equation, the effects of MBS hedging can be readily understood. An increase in hedging intensity, reflected in an increase in $\gamma$, raises the average level of volatility (the first term on the right-hand side). This effect arises because any future shocks (with volatility determined by $\alpha_{0}$ ) will be amplified - which was our original motivation for focusing on 
volatility. But it turns out that mortgage hedging has additional effects. In particular, there is a "volatility of volatility" effect (the third term), whereby any change in expected volatility will be larger when hedging activity is intense. Lastly, there is an effect on the autocorrelation of volatility (the second term). However, this effect is relatively inconsequential. As we will see below, hedging intensity is persistent enough that the ratio of $\gamma_{t+1}$ to $\gamma_{t}$ is typically close to 1 , so that this term can be largely ignored.

An important issue, of course, is determining the variables that might be associated with the hedging associated with mortgage prepayment risk - or the determinants of $\gamma$. We consider three alternatives:

1. The convexity of the MBS market. The convexity of a security measures the sensitivity of its duration to changes in market interest rates. Thus, if all MBS investors were attempting to maintain the duration of their portfolios, the convexity of aggregate MBS holdings would determine the extent to which they would have to adjust their hedging positions in response to a change in market interest rates. In the analysis, we measure convexity in terms of the dollar amount of ten-year swaps that would be required to offset changes in duration of outstanding MBS.

2. The duration of the $M B S$ market. Another measure of prepayment risk is the duration of the aggregate MBS market, which will decline when the prepayment of outstanding MBS becomes more likely. This measure may be inferior to the convexity of the MBS market, because prospective hedging activity should be related to changes in duration rather than its level (see the discussion in the previous section). For example, if interest rates fell sufficiently, it is possible that the prepayment option in outstanding MBS would move close enough to being in the money that duration would start to become less sensitive to changes in rates. In the analysis below, we use the decline in duration attributable to prepayment risk, which is proxied by the difference between the duration of the MBS and the duration of the ten-year swap. As with convexity, we measure this duration gap in terms of the dollar equivalent of ten-year swaps.

3. The amount of mortgage refinancing. As a third measure, we use the dollar amount of refinancing activity computed from the index provided by the Mortgage Bankers Association. This measure is less appealing for our purposes because it measures realized refinancing activity rather than prospective refinancing activity. Nevertheless, it is a data series that is commonly referred to in market commentary, and one that is easy to obtain. 
We compute the dollar amount of refinancing by multiplying the MBA refinancing index by the average size of originated loans.

Computing the convexity or duration of outstanding mortgage-backed securities is not a straightforward calculation, as it is for other debt securities. It requires one to estimate a mortgage prepayment model, which of course will depend on the distribution of coupon for outstanding mortgages, the prepayment inclinations of different cohorts of mortgage payers, and the volatility of mortgage rates going forward. Since this paper does not aim to make a contribution to the specification of prepayment models, we simply employ measures of convexity and duration that are computed by Merrill Lynch and reported on Bloomberg.

For simplicity, we choose a specification in which the amplification factor $\gamma$ is a linear function of one of these variables:

$$
\gamma_{t}=1+\beta X_{t}
$$

where $X_{t}$ is one of the three measures of hedging intensity. According to equation (6), there is no amplification $\left(\gamma_{t}=1\right)$ when the variable $X_{t}$ is at zero. ${ }^{7}$ Under the three measures considered, respectively, this situation arises when duration has no sensitivity to market interest rates, when prepayment risk has no effect on the duration of mortgage hedging, or when there is no refinancing activity. The amplification factor presumably will begin to increase when mortgage convexity becomes more negative, when mortgage duration declines relative to swap duration, or when refinancing activity increases.

The linear specification is chosen primarily for its simplicity, and admittedly it may be somewhat imprecise. It could very well be that the amplification is not linear in the hedging activity, but rather increases faster the stronger hedging becomes. In general, we could have specified a functional form of the type $\gamma_{t}=f\left(X_{t}-\bar{X}\right)$; this specification, however, would have required us to estimate at least one more parameter, $\bar{X}$, in addition to choosing one among the infinitely many nonlinear specifications for $f$.

With the functional form specified for $\gamma$, the specific version of equation (5) that we implement is:

$$
\sigma_{\Delta r, t}^{2}=\alpha_{0}+\alpha_{0} \beta X_{t}+\alpha_{1} \frac{1+\beta X_{t}}{1+\beta X_{t-1}} \sigma_{\Delta r, t-1}^{2}+\left(1+\beta X_{t}\right) u_{t}
$$

One approach would be to estimate equation (7) directly. However, this approach is complicated by the endogeneity of the variable $X_{t}$. Indeed, the measured duration and convexity

\footnotetext{
${ }^{7}$ Because the variables that we use for $X_{t}$ are never precisely zero, we subtract off the value that is closest to zero over the sample.
} 
of outstanding MBS will depend directly on the expected level of volatility - and hence will obviously be influenced by the error term $u_{t}$.

To account for this problem, we must use an instrumental variables (IV) approach. However, it is not straightforward to apply an IV estimator to equation (7), because the endogenous variable enters not only as a regressor, but also as a scalar term multiplying the residual. As a simple solution, we note that the measures of MBS hedging intensity are quite persistent (especially at the weekly frequency that we consider below), so that the lagged value of $X_{t}$ probably serves as an effective instrument for that variable. Indeed, if we regress each variable on its own lag, the estimated coefficient is above 0.96 in each case, and the $R^{2}$ statistic in each case is above 0.92 .

If we allow the lagged value of the variable $X_{t}$ to serve as its instrument, then equation (7) reduces to the following simple equation:

$$
\sigma_{\Delta r, t}^{2}=\alpha_{0}+\alpha_{0} \beta X_{t-1}+\alpha_{1} \sigma_{\Delta r, t-1}^{2}+\left(1+\beta X_{t-1}\right) u_{t}
$$

As discussed above, the parameter $\beta$, which determines the amount of amplification, enters in two ways - as a coefficient in the regression, which captures the direct impact of MBS hedging on the level of volatility; and as a scale term multiplying the error term, which captures the volatility-of-volatility effect. Because of this, equation (8) must be estimated through maximum likelihood, where the likelihood function is given by:

$$
L\left(\alpha_{0}, \alpha_{1}, \beta, v\right)=-\frac{1}{2} \ln \left(v\left(1+\beta X_{t-1}\right)^{2}\right)-\frac{1}{2 v}\left(\sigma_{\Delta r, t}^{2}-\alpha_{0}\left(1+\beta X_{t-1}\right)-\alpha_{1} \sigma_{\Delta r, t-1}^{2}\right)^{2},(9)
$$

where $v$ is the variance of the innovation $u$.

As an alternative, we could simply ignore the volatility-of-volatility effect and estimate equation (8) using an ordinary least-squares regression of the expected volatility on its own lag and on the variable $X_{t-1}$. We pursue this approach both because it serves as a robustness check, and because it allows us to determine whether our estimates of $\beta$ are driven by the level-of-volatility effect or by the volatility-of-volatility effect.

\section{Results}

In this section we estimate equation (8) using the three proxies of mortgage hedging activity described above. Our dataset consists of weekly data for the implied volatility of the ten-year swap rate over various horizons, the effective convexity and duration of the Merrill-Lynch 
master mortgage index (measured by the dollar equivalent of ten-year swaps), and the dollar value of mortgage refinancing computed from the MBA refinancing index. The sample runs from January 31, 1997 to May 23, 2003, which provides a total of 330 weekly observations.

Some summary statistics of the three hedging measures are presented in Table 1. According to the most recent readings from the market, the convexity of the market was about -\$578 billion. In other words, as noted above, in response to a 50 basis point fall (rise) in market interest rates, MBS holders (in the aggregate) would have had to agree to receive (pay) fixed payments in $\$ 289$ billion of new ten-year swap agreements to maintain their duration. $^{8}$ The duration measure was at $-\$ 3.337$ trillion, indicating that MBS holders would have to receive fixed payments in that amount of ten-year swaps to completely make up the duration lost from prepayment risk (or, more specifically, to make up the difference in duration between all outstanding MBS and comparable swaps). Lastly, refinancing activity in the last week of our sample was very heavy, with a total volume of $\$ 201$ billion dollars for that week alone. The table also shows the average level of all the variables in each year included in our sample. As can be seen, prepayment risk has been particularly elevated in 2003, as long-term interest rates have fallen to unusually low levels.

We are interested in investigating how these measures affect the expected volatility of the ten-year swap rate. To measure expected volatility, we rely on the swaption market. Swaptions, which are options to enter into a swap agreement at some future date, are actively traded instruments. The prices of swaptions are commonly used to derive a measure of implied volatility, which represents investors' expectations at time $t$ of the volatility of the underlying swap rate expected over the horizon of the option contract. In the analysis that follows, we will measure implied volatility in terms of basis points. ${ }^{9}$ Whereas implied volatility is usually expressed to represent the standard deviation of interest rate changes over the horizon of the option, the model above instead focuses on the expected variance of the interest rate. Thus, in the empirical analysis we will use the squared value of implied volatility - which we will refer to as implied variance.

Implied volatility from swaptions can be measured for different maturities of the under-

\footnotetext{
${ }^{8}$ As noted earlier, this calculation is only a first order approximation. The dollar amount of hedging required for increasing and decreasing rates would not be symmetric.

${ }^{9}$ Our results are much stronger if we use the other convention for measuring implied volatility - as a percent of the rate. However, we believe that using this measure may be misleading. Implied volatility measured in percent tends to be highly negatively correlated with the level of interest rates, because a given basis points change in rates becomes a larger percent of the rate as the rate falls. This tends to create a spurious correlation between volatility and mortgage hedging.
} 
lying swap and for different horizons for the expiration of the option. Here we are primarily interested in $3 m \times 10 y$ swaptions, which are options to enter into a ten-year swap in three months. The choice of the ten-year swap is motivated by the fact that there is significant hedging activity in ten-year instruments (see [1] and [2]), and thus one would expect to see amplification effects for rates at that horizon. The choice of the three-month-ahead horizon for the option reflects an assumption that mortgage hedging should have only short-term effects. Indeed, while we suspect that the hedging of mortgage prepayment risk can amplify movements in long-term interest rates over short horizons, we believe that those effects diminish over time so that, in the long run, interest rates are driven by fundamental factors.

Even short-term volatility, though, is affected by factors other than mortgage hedging. To help isolate the effects of mortgage hedging, we focus on movements in short-run volatility that are unrelated to shifts in the rest of the volatility term structure. More specifically, we first regress the three-month ahead implied variance on the two-year ahead implied variance,

$$
\sigma_{\Delta r, t}^{2}(3 m \times 10 y)=\psi_{0}+\psi_{1} \sigma_{\Delta r, t}^{2}(2 y \times 10 y)+\varsigma_{t},
$$

and we then use the results to derive an orthogonalized measure of short-term variance, $\sigma_{\Delta r, t}^{2}=\varsigma_{t}+\bar{\sigma}_{\Delta r, t}^{2}(3 m \times 10 y)$, where $\bar{\sigma}_{\Delta r, t}^{2}(3 m \times 10 y)$ is the sample average of $3 m \times 10 y$ variance. ${ }^{10}$ The actual measure of implied variance, $\sigma_{\Delta r, t}^{2}(3 m \times 10 y)$, and the orthogonalized measure, $\sigma_{\Delta r, t}^{2}$, are shown in Figure 2 .

The results of the estimation of equation (8) using this measure of implied variance are shown in Table 2. All of the estimated parameters are significant and have the expected signs. The variance of the fundamental shock is persistent $\left(\alpha_{1}>0\right)$, has a positive mean $\left(\alpha_{0}>0\right)$, and is itself influenced by stochastic innovations $(v>0)$. Of greater relevance for the current paper, the amplification coefficient $\beta$ in each case has the expected sign and is strongly significant. For the convexity and duration measures, $\beta$ is negative, indicating that an increase in prepayment risk that makes convexity more negative or reduces duration is associated with an increase in the expected variance of the ten-year swap rate. For the refinancing measure, $\beta$ is positive, indicating that an increase in the dollar volume of refinancings is also associated with an increase in the expected variance.

The magnitude of these effects can be gauged from the implied behavior of the amplification factor, $\sqrt{\gamma_{t}}$, which is shown for each measure in Figure 3. All three measures indicate

\footnotetext{
${ }^{10}$ The coefficients in equation $(10)$ are $\psi_{0}=-0.631$ and $\psi_{1}=1.827$, with large t-statistics and an $R^{2}$ of 0.95 .
} 




Figure 2: Actual and orthogonalized implied variances

that mortgage hedging added volatility to the market in 1998 and early 1999, and then again beginning in 2001. The more recent run-up in mortgage-related volatility has been considerable and has persisted for some time. Under the convexity measure, amplification has averaged about 16 percent over the first five months of 2003, which means that a fundamental shock that would normally cause a 50 basis point movement on long-term rates would instead induce a 58 basis point response. Amplification under the other measures has been even larger, with average levels of 22 percent and 28 percent under the duration and refinancing measures, respectively, over that period. ${ }^{11}$

Similar results are found if we ignore the volatility-of-volatility effect in equation (8) and simply regress the implied variance on a constant, its own lag, and the mortgage-hedging variable lagged one period (as an instrument for itself). The estimated coefficients, shown in Table 3, are also significant and have similar quantitative implications for the amount of amplification. ${ }^{12}$ Thus, it appears that much of the amplification effects that are found arise to a considerable extent through the association of the mortgage-hedging variables with the level of implied volatility, rather than the magnitude of changes in implied volatility.

\footnotetext{
${ }^{11}$ The refinancing index has sharp spikes that make it hard to summarize its recent level.

${ }^{12}$ Without the volatility of volatility effect, the regression we estimate is $\sigma_{\Delta r, t}^{2}=\alpha_{0}+\alpha_{0} \beta X_{t-1}+\alpha_{1} \sigma_{\Delta r, t-1}^{2}+$ $u_{t}$, and therefore the coefficient of $X_{t-1}$ is $\alpha_{0} \beta$.
} 


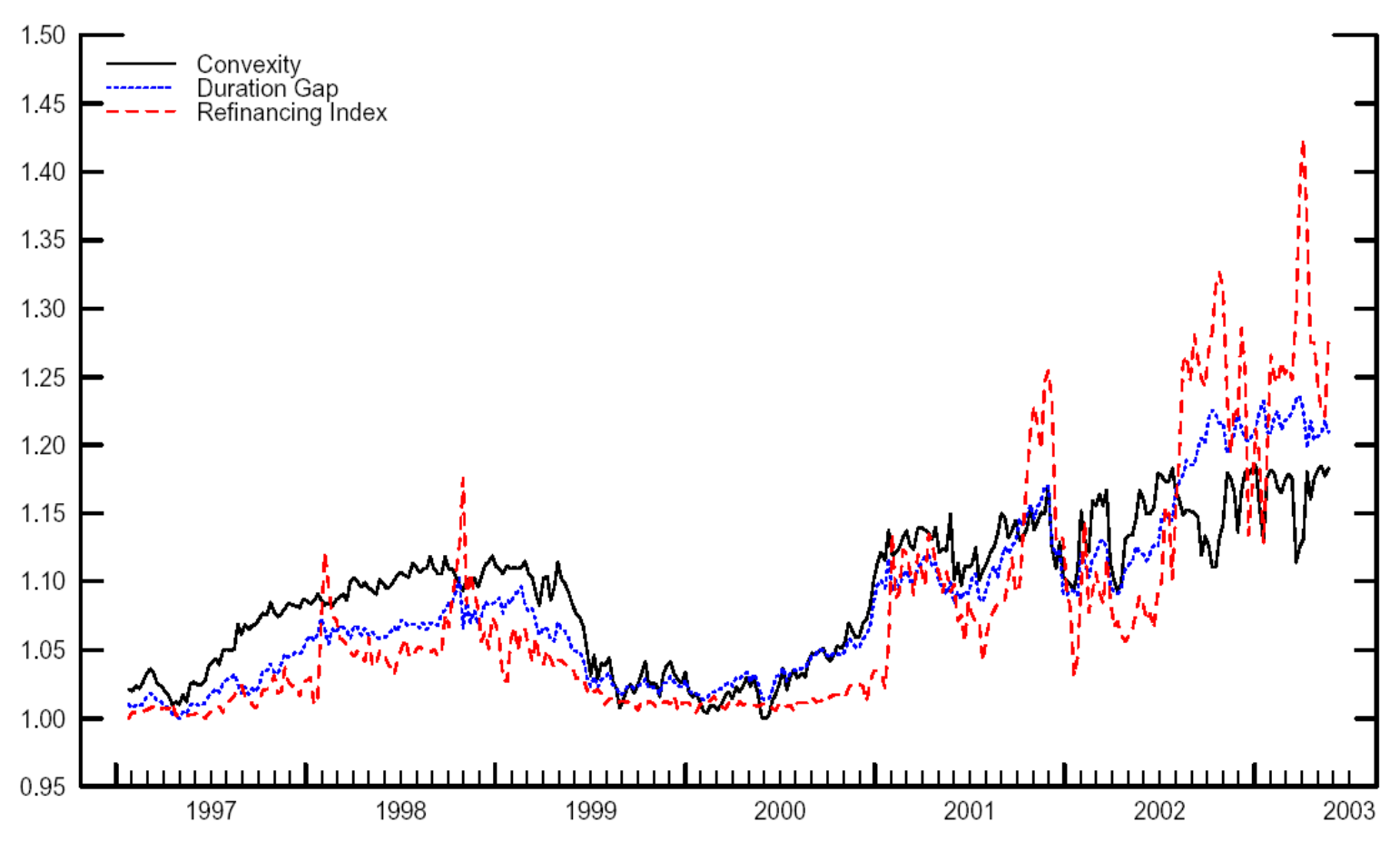

Figure 3: Amplification factor under the three hedging measures

We briefly consider the robustness of our finding to two modifications. First, we assess whether the results go through if we use the level of $3 m \times 10 y$ swaption implied variance, rather than the component that is orthogonal to the variance over longer horizons. The results in this case, shown in Table 4, provide the same conclusions as above, with the amplification parameter in each cases coming in even larger and more significant. We are somewhat reluctant to attribute these larger amplification factors to mortgage hedging, though, given our view that the effects should primarily be realized at relatively short horizons. ${ }^{13}$

Second, we investigate what happens if we replace implied volatility with actual volatility. Implied volatility has some advantages in our framework, in that it reflects investors perceptions about how future shocks will influence long-term interest rates. Realized volatility, of course, will also be influenced by unexpected events that take place over the horizon considered. But because those unexpected events will be uncorrelated with the explanatory variables, we can simply replace implied volatility by actual volatility in the estimation. We measure actual volatility by the standard deviation of daily changes in the ten-year

\footnotetext{
${ }^{13}$ We argued above that the level of $3 m \times 10 y$ volatility is influenced by other factors. It is difficult to assess whether those factors would cause the estimated beta parameters to rise, given that the regression has effects arising both through the level of volatility and the magnitude of its changes.
} 
swap rate over the following month, and we include this variable on the right-hand side of equation (8) with a lag of one month.

The results for actual volatility, presented in Table 5, again replicate the pattern we found for implied volatility. Most importantly, the estimate of coefficient $\beta$ is always significant and always has the right sign. The amounts of amplification, however, are larger than those from Table 2. Again, as in Table 4, this finding may reflect that by using actual volatility, we are unable to isolate the component of volatility over the short run that is not also passed through into longer-run volatility.

Overall, the results provide evidence that periods during which MBS investors face considerable prepayment risk are associated with an increase in the expected volatility of the ten-year swap rate over short horizons, consistent with the notion that hedging activity amplifies expected rate movements.

\section{Conclusions}

The sheer size of the mortgage market implies that efforts by investors to hedge the prepayment risk of those securities can result in sizable shifts in the demand for other fixed-income securities. This paper presents statistical evidence that this hedging activity tends to amplify movements in the ten-year swap rate - as indicated by the increase in near-term implied volatility during periods when prepayment risk is elevated. The results indicate that these effects are statistically significant and considerable in magnitude, with recent amplification

levels of between 16 percent and 30 percent. Moreover, we assume that the effects are short-lived.

The increase in implied volatility during periods of hedging lends itself to two interpretations. Throughout the paper, we have argued that it reflects the expected amplification effects arising from dynamic hedging strategies. An alternative interpretation is that it reflects significant shifts in the supply of convexity; as prepayment risk increases, for example, a considerable amount of convexity flows out of the fixed-income market and to the balance sheets of mortgage payers. Because mortgage investors will be seeking convexity, the value of swaptions - and hence the implied volatility on those instruments-will increase. The effects will be most pronounced for shorter-term options, since they have more exposure to "gamma" risk.

Note, however, that these two interpretations go hand in hand. After all, market partic- 
ipants can supply swaptions through dynamic hedging, in which case the cost of "creating" the swaption will depend importantly on the expected volatility of the swap rate. Thus, if there were no amplification effects, the market could accommodate the increased demand for convexity without any implications for its price. Thus, the response of implied volatility that we find must reflect the expectation that the mortgage hedging will result in greater volatility of swap rate movements.

Our findings are relevant to market participants in a number of ways. Having an estimate of the extent to which the volatility of interest rate movements respond to mortgage hedging activity is crucial for determining the anticipated costs of dynamic hedging strategies and the appropriate cost of static strategies. More generally, the identified effects have implications for the pricing of any assets with exposure to the volatility of market interest rates. The most obvious example is swaptions, for which our estimates provide very direct evidence of the risks associated with mortgage hedging. The results also have implications for the risks of a much wider set of assets whose values depend either directly or indirectly on long-term interest rates.

\section{References}

[1] Crawford, A., P. Check, M. Huie and A. Kocic (2003): Special Report - Mortgage Market Influence on Derivatives, U.S. Fixed Income Weekly, Deutsche Bank, February 7.

[2] Fernald, J.D., F. Keane and P.C. Mosser (1994): Mortgage Security Hedging and the Yield Curve, Federal Reserve Bank of New York Quarterly Review, Summer-Fall.

[3] Goodman, L. and J. Ho (2001): Hedging Mortgages with Swaps and Agencies. In Fabozzi, F.J. (editor), The Handbook of Mortgage-Backed Securities.

[4] Jaffee, D. (2003): The Interest Rate Risk of Fannie Mae and Freddie Mac, manuscript, Haas School of Business, University of California Berkeley, http://faculty.haas.berkeley.edu/jaffee/FinalJFSR.pdf, forthcoming, Journal of Financial Services Research.

[5] Kambhu, J. and P.C. Mosser (2001): The Effect of Interest Rate Options Hedging on Term-Structure Dynamics, Federal Reserve Bank of New York Quarterly Review, December. 


\begin{tabular}{lcccccccc}
\hline \hline & \multicolumn{7}{c}{ Yearly Averages } & \\
& 1997 & 1998 & 1999 & 2000 & 2001 & 2002 & 2003 & Recent \\
\hline \multirow{2}{*}{ Dollar Convexity } & -275 & -505 & -312 & -231 & -624 & -723 & -790 & -578 \\
Dollar Duration Gap & -1258 & -1674 & -1428 & -1402 & -2067 & -2521 & -3108 & -3337 \\
Dollar Refinancing & 9 & 30 & 15 & 10 & 53 & 75 & 139 & 201 \\
\hline
\end{tabular}

Table 1: Summary statistics for three hedging proxies (in $\$$ billions)

\begin{tabular}{lcccc}
\hline \hline & \multicolumn{5}{c}{ Estimated Parameters- } \\
& $\alpha_{0}$ & $\alpha_{1}$ & $\beta$ & $v$ \\
\hline \multirow{3}{*}{ Dollar Convexity } & 0.1103 & 0.8867 & -0.4877 & 0.0082 \\
& $(5.20)$ & $(43.84)$ & $(-3.12)$ & $(8.68)$ \\
& & & & \\
Dollar Duration Gap & 0.1169 & 0.8817 & -0.2375 & 0.0084 \\
& $(5.19)$ & $(38.09)$ & $(-2.66)$ & $(7.87)$ \\
Dollar Refinancing & 0.1349 & 0.8649 & 4.9671 & 0.0085 \\
& $(5.10)$ & $(31.04)$ & $(3.16)$ & $(8.58)$ \\
& & & &
\end{tabular}

T-stats in parentheses. Hedging variables measured in $\$$ trillions.

Table 2: MLE results for orthogonalized implied variance

\begin{tabular}{lccc}
\hline \hline & \multicolumn{3}{c}{ Estimated Parameters- } \\
& $\alpha_{0}$ & $\alpha_{1}$ & $\alpha_{0} \beta$ \\
\hline \multirow{3}{*}{ Dollar Convexity } & 0.1000 & 0.8856 & -0.0846 \\
& $(2.42)$ & $(19.35)$ & $(-2.69)$ \\
Dollar Duration Gap & 0.1097 & 0.8859 & -0.0313 \\
& $(2.45)$ & $(18.35)$ & $(-2.24)$ \\
Dollar Refinancing & 0.1211 & 0.8816 & 0.5033 \\
& $(2.60)$ & $(18.55)$ & $(2.36)$
\end{tabular}

T-stats in parentheses. Hedging variables measured in $\$$ trillions.

Table 3: Regression results for orthogonalized implied variance 


\begin{tabular}{lcccc}
\hline \hline & \multicolumn{5}{c}{ Estimated Parameters- } \\
& $\alpha_{0}$ & $\alpha_{1}$ & $\beta$ & $v$ \\
\hline \multirow{3}{*}{ Dollar Convexity } & 0.0736 & 0.9100 & -1.0171 & 0.0123 \\
& $(2.83)$ & $(44.03)$ & $(-3.79)$ & $(6.42)$ \\
\multirow{5}{*}{ Dollar Duration Gap } & 0.0904 & 0.8851 & -0.6211 & 0.0113 \\
& $(3.63)$ & $(44.17)$ & $(-5.42)$ & $(7.85)$ \\
Dollar Refinancing & 0.0899 & 0.8924 & 11.9142 & 0.0012 \\
& $(3.57)$ & $(43.33)$ & $(7.93)$ & $(11.83)$ \\
& & & &
\end{tabular}

T-stats in parentheses. Hedging variables measured in $\$$ trillions.

Table 4: MLE results for non-orthogonalized implied variance

\begin{tabular}{lcccc}
\hline \hline & \multicolumn{5}{c}{ Estimated Parameters- } \\
& $\alpha_{0}$ & $\alpha_{1}$ & $\beta$ & $v$ \\
\hline \multirow{3}{*}{ Dollar Convexity } & 0.0292 & 0.7226 & -0.8316 & 0.0003 \\
& $(2.99)$ & $(9.69)$ & $(-2.24)$ & $(3.74)$ \\
& & & & \\
Dollar Duration Gap & 0.0273 & 0.7363 & -0.4964 & 0.0003 \\
& $(2.82)$ & $(9.64)$ & $(-2.38)$ & $(3.74)$ \\
Dollar Refinancing & 0.0330 & 0.7191 & 5.9163 & 0.0004 \\
& $(3.56)$ & $(10.86)$ & $(2.69)$ & $(5.48)$ \\
& & & & \\
\hline
\end{tabular}

T-stats in parentheses. Hedging variables measured in $\$$ trillions.

Table 5: MLE results for realized volatility 